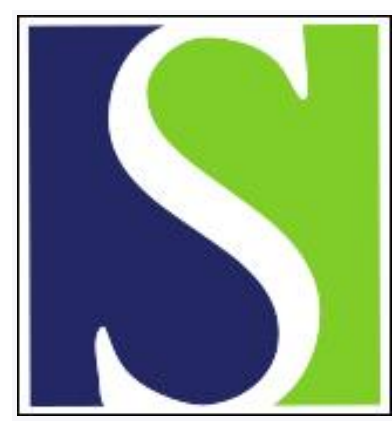

Scand J Work Environ Health 1993;19(5):297-312

https://doi.org/10.5271/sjweh.1470

Issue date: 01 Oct 1993

Psychosocial factors at work and musculoskeletal disease.

by Bongers PM, de Winter CR, Kompier MA, Hildebrandt VH

Affiliation: TNO Institute of Preventive Health Care, Leiden, The Netherlands.

The following articles refer to this text: 2016;42(2):125-134;

2020;46(1):1-4

This article in PubMed: www.ncbi.nlm.nih.gov/pubmed/8296178 


\title{
Psychosocial factors at work and musculoskeletal disease
}

\author{
by Paulien M Bongers, PhD, Cornelis R de Winter, PhD, Michiel AJ Kompier, PhD, \\ Vincent $\mathrm{H}$ Hildebrandt, $M \mathrm{D}^{1}$
}

\begin{abstract}
BONGERS PM, de WINTER CR, KOMPIER MAJ, HILDEBRANDT VH. Psychosocial factors at work and musculoskeletal disease. Scand $J$ Work Environ Health 1993;19:297-312. The objective of this review is to establish whether the epidemiologic literature presents evidence of an association between psychosocial work factors and musculoskeletal disease. In a hypothetical model it is suggested that individual characteristics and stress symptoms can modify this relationship. The reviewed studies do not present conclusive evidence due to high correlations between psychosocial factors and physical load and to difficulties in measuring dependent and independent variables. Nevertheless, it is concluded that monotonous work, high perceived work load, and time pressure are related to musculoskeletal symptoms. The data also suggest that low control on the job and lack of social support by colleagues are positively associated with musculoskeletal disease. Perceived stress may be an intermediary in this process. In addition, stress symptoms are often associated with musculoskeletal disease, and some studies indicate that stress symptoms contribute to the development of this disease.
\end{abstract}

Key terms: back pain, musculoskeletal symptoms, neck pain, psychological factors, review, shoulder pain, stress.

Work-related musculoskeletal disease (in particular back pain and back disorders) accounts for a large number of workers' compensation days and disability in numerous countries. In the last decade disability due to musculoskeletal disease was still increasing, making work-related musculoskeletal problems one of the most expensive health problems in modern industrial society. Data from the American National Center for Health Statistics show that the number of people disabled from back pain increased by $168 \%$ between 1971 and 1986; this increase is 14 times faster than the population growth (1).

It is generally agreed that back pain and other musculoskeletal diseases are of multifactorial origin. Many epidemiologic studies have been concerned with the relationship between musculoskeletal disease and physical load during work. (See, for example, references 2-4.) Some of these studies report an association, while others do not. Several authors have presented possible explanations for the sometimes weak or contradictory evidence for the relationship between physical load and musculoskeletal disease. Poor measurement of current and historical exposure, lack of a specific diagnosis, and healthbased selection in industry are the most important explanations. Nevertheless, heavy physical work, prolonged static load, and motor vehicle driving are generally accepted as risk factors for back trouble, and repetitive and static work load are considered risk factors for neck and shoulder trouble.

TNO Institute of Preventive Health Care, Leiden, The Netherlands.

Reprint requests to: Dr PM Bongers, TNO Institute of Preventive Health Care, PO Box 124, 2300 AC Leiden, The Netherlands.
In addition to physical load, several individual factors (eg, age, previous symptoms) seem to pose risks for musculoskeletal complaints. It is generally agreed though that work-related physical load in relation to individual functional capacity can only partially explain the high prevalence of musculoskeletal disease. Walsh et al (5) estimated that, for symptoms of the back, the etiologic fraction explained by physical load is only $20 \%$. Recently the potential etiologic significance of psychosocial factors to musculoskeletal trouble has received increasing attention. Analysis of the role of these variables in the development of musculoskeletal trouble may contribute to the understanding and reduction of work-related musculoskeletal disease and disability. To our knowledge, no review of the epidemiologic literature on this relationship has been published earlier. Since, in our opinion, the studies concerning this topic are too heterogeneous to combine in a meta-analysis, we conducted a qualitative literature review.

The epidemiologic studies on the relationship between psychosocial variables and musculoskeletal disease are heterogeneous in study design, measurement of outcome, and the psychosocial variables studied. These studies originate from three different traditions of research: (i) studies on the relationship between (work-related) stressors, stress, and symptoms of ill health; (ii) studies on personality and psychological disorders of chronic (back-) pain patients; and (iii) epidemiologic studies on the determinants of musculoskeletal disease. The main concepts used in these research areas are briefly illustrated in the following text.

1. Stress can arise when people feel unable to cope with the demands placed upon them. Personal char- 
acteristics such as age, gender, experience, ambition, needs, and personality influence coping capacity. According to Karasek et al (6) high work demands, lack of clarity, and conflict at work are among the relevant work-related characteristics which can predict job dissatisfaction, work stress, and ill health. The effect of these variables is moderated by low control over work, poor career development opportunities, and poor social support at work. In particular, the combination of high demands and low control at work is reported to be stressful and is related to adverse health effects. Most reports in the literature on the relationship between stress and adverse health effects have analyzed the relevance of stress to the development of heart disease, gastrointestinal problems, or poor subjective health in general. (See, for example, references 7 and 8.) Only very few of these studies have investigated the relationship between work stress and musculoskeletal symptoms.

2. The correlation between personality, psychological problems, and chronicity of musculoskeletal pain has been extensively studied in the clinical setting $(9,10)$. Although the focus in this area of research has been on the chronic pain patient, the results of these studies support the opinion that individual psychological capacity is important when musculoskeletal symptoms are being dealt with. These individual factors may not only be important for the exacerbation or continuation of symptoms, but also for the development of symptoms.

3. In epidemiologic research on musculoskeletal disease, individual capacity has mainly been interpreted as physical capacity (eg, muscle strength, range of movement), whereas little attention has been given to psychological coping capacity or the interaction between physical load and coping capacity. In this area of research the focus has mainly been on mechanical factors. The mechanical load is partly determined by worker organization variables such as speed of work and variation in tasks (eg, posture).
When the concepts of these three research traditions are combined and applied to the subject of this literature review, the following associations between psychosocial factors, stress, individual characteristics, and musculoskeletal disease are suggested (illustrated in figure 1):

1. Psychosocial factors at work directly influence the mechanical load through changes in posture, movement, and exerted forces. (For example, time pressure may increase hurried movements with high accelerations or poor posture.)

2. Psychosocial factors at work (demands and factors such as job control and social support), together with the personal capacity to cope with such factors, may increase work-related stress (stress symptoms). This increase in stress may (a) increase muscle tone, which may in the long term lead to the development of musculoskeletal symptoms or increase musculoskeletal symptoms due to some other, yet unknown but specific physiological mechanism (eg, hormonal path), (b) moderate the relationship between mechanical load and musculoskeletal symptoms due to enhancement of the perception of symptoms or the reduction of the capacity to cope with them. Therefore the symptoms due to mechanical loading may be prolonged or intensified, or symptoms of poor health in general, including musculoskeletal symptoms, may increase.

Thus stress may either increase musculoskeletal signs in itself or increase the perception of symptoms due to other risk factors. We do not pretend to present an explanatory model. Figure 1 serves mainly an illustrative purpose and provides a structure for the discussion of possible associations between psychosocial factors and musculoskeletal disease presented in the literature. In table 1 all of the factors indicated in figure 1 are clustered into five categories. This division seemed the most appropriate from the practical and theoretical point of view, although it can be argued that some of these variables could as well belong to other categories. For example, de-

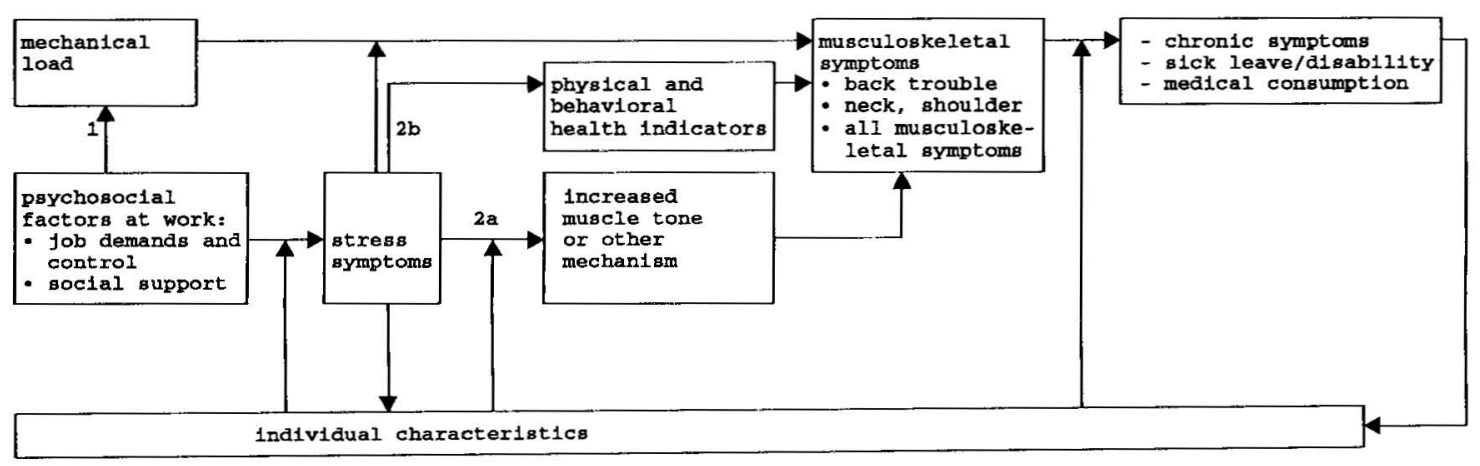

Figure 1. Possible associations of psychosocial factors at work with stress and musculoskeletal symptoms 
pressive symptoms can also be regarded as stress symptoms, and job dissatisfaction does not properly fit in any of the categories. In the following description and discussion of the literature, attention is given to each of these clusters.

In summary, the main questions of this literature review are (i) to what extent are the psychosocial factors at work (demand, control, and support variables) related to musculoskeletal symptoms, in particular back, neck, or shoulder symptoms; (ii) do individual (psychological) characteristics influence this relationship; and (iii) what is the role of stress symptoms in this process, and is the relationship between psychosocial factors at work and musculoskeletal symptoms a specific relationship or is it the result of a general detrimental effect of these variables on health or health behavior?

\section{Methods}

\section{Selection of the literature}

The available literature was selected in an automatic search of several data bases, OSH-ROM, CIS-DOC, Psychinfo and Medline, a manual searching through Current Contents (Life Sciences and Social Sciences), Psychological Abstracts, Safety and Health at Work, ILO/CIS Bulletin, and CIS-Abstracts, a screening of recent issues of scientific journals on occupational musculoskeletal disorders and work-related stress, and a check of the relevant references in recent publications on the subject. Initially, all studies analyzing the relationship between musculoskeletal disease and any of the variables in table 1 were selected. However, studies focusing on determinants of the prognosis of (chronic) back pain in patients $(12-14)$ were not included, since the main objective of this review is to investigate the influence of psychosocial variables on the development of musculoskeletal problems, not its influence on prognosis. In this presentation the emphasis is on work-related psychosocial factors, and therefore the influence of psychosocial factors in the nonwork situation, such as emotional life events, problems at home, or living alone, are not discussed. These variables are included in a more extensive report on the subject (15). Descriptive studies that did not compare the results of exposed workers to a reference population of non- or less-exposed workers were also excluded. No other exclusion criteria were applied.

\section{Presentation of the literature}

Because there are no a priori hypotheses on the similarity of the relationships between psychosocial factors and symptoms of each musculoskeletal site, the studies on symptoms of the back, the neck and shoulder region, and the musculoskeletal system (several or all sites combined) are discussed separately. The results of cross-sectional and longitudinal studies are
Table 1. Five categories of factors that may be associated with musculoskeletal symptoms. (MMPI = Minnesota Multiphasic Personality Inventory)

\begin{tabular}{|c|c|}
\hline Category & Factor \\
\hline $\begin{array}{l}\text { Psychosocial factors at work - } \\
\text { demands and control }\end{array}$ & $\begin{array}{l}\text { Monotonous work } \\
\text { Time pressure } \\
\text { High concentration } \\
\text { High responsibilities } \\
\text { High work load } \\
\text { Few opportunities to take breaks } \\
\text { Lack of clarity } \\
\text { Low control and little autonomy }\end{array}$ \\
\hline $\begin{array}{l}\text { Psychosocial factors at work - } \\
\text { social support }\end{array}$ & $\begin{array}{l}\text { Poor social support from colleagues } \\
\text { Poor social support from superiors }\end{array}$ \\
\hline \multirow[t]{4}{*}{ Individual characteristics } & $\begin{array}{l}\text { Personality type } \\
\text { Neuroticism } \\
\text { Hysteria, anti-social (MMPI) }\end{array}$ \\
\hline & $\begin{array}{l}\text { Type A behavior } \\
\text { Extrovert personality } \\
\text { Psychological dysfunctioning }\end{array}$ \\
\hline & Depression \\
\hline & $\begin{array}{l}\text { Coping styles } \\
\text { Attitude towards own health } \\
\text { Low social class } \\
\text { Low educational level }\end{array}$ \\
\hline Stress symptoms & $\begin{array}{l}\text { Worry, tension, anxiety } \\
\text { Physical stress symptoms } \\
\text { Fatigue or exhaustion } \\
\text { High perceived work stress } \\
\text { Low job satisfaction } \\
\text { Physiological parameters }\end{array}$ \\
\hline $\begin{array}{l}\text { Physical and behavioral health } \\
\text { indicators }\end{array}$ & $\begin{array}{l}\text { Poor physical health } \\
\text { Respiratory disease or cough } \\
\text { Stomach trouble } \\
\text { Cardiovascular disease } \\
\text { Headache } \\
\text { Use of medication } \\
\text { Use of medical services }\end{array}$ \\
\hline
\end{tabular}

also presented separately, since the results of the cross-sectional studies can suffer from bias due to differential health-based selection and do not provide information on the temporal relationship between events. In addition, comments are made on the study population and whether the study dealt with potential confounders (in particular physical load). The presentation of the longitudinal studies includes mention of adjustment for a history of musculoskeletal pain at the start of follow-up. A more extensive description of the literature is presented in another report (15).

\section{Results}

\section{Back pain and back disorders}

All of the studies relating the variables of table 1 to back trouble are presented in table 2 (chronological order).

The cross-sectional epidemiologic studies on back pain and back disorders were heterogeneous in design, outcome variable, independent variables, and the way potential confounders were treated. Most of the studies on the working population dealt with work-related variables, either self-reported psychosocial factors during work or perceived stress during work (16-21). Few of the population-based 
Table 2. Summary of the associations between back pain (BP) and back disorders (BD) and psychosocial factors at work demands and control (A), psychosocial factors at work - social support (B), individual characteristics (C), stress symptoms (D), physical and behavioral health indicators $(E) .(+=$ positive association, $++=$ positive association after adjustment for confounder, $+1-=$ conflicting data, $-=$ no association; $O=$ not studied, LBP $=$ low-back pain, $\mathrm{HNP}=$ hernia nuclei pulposi)

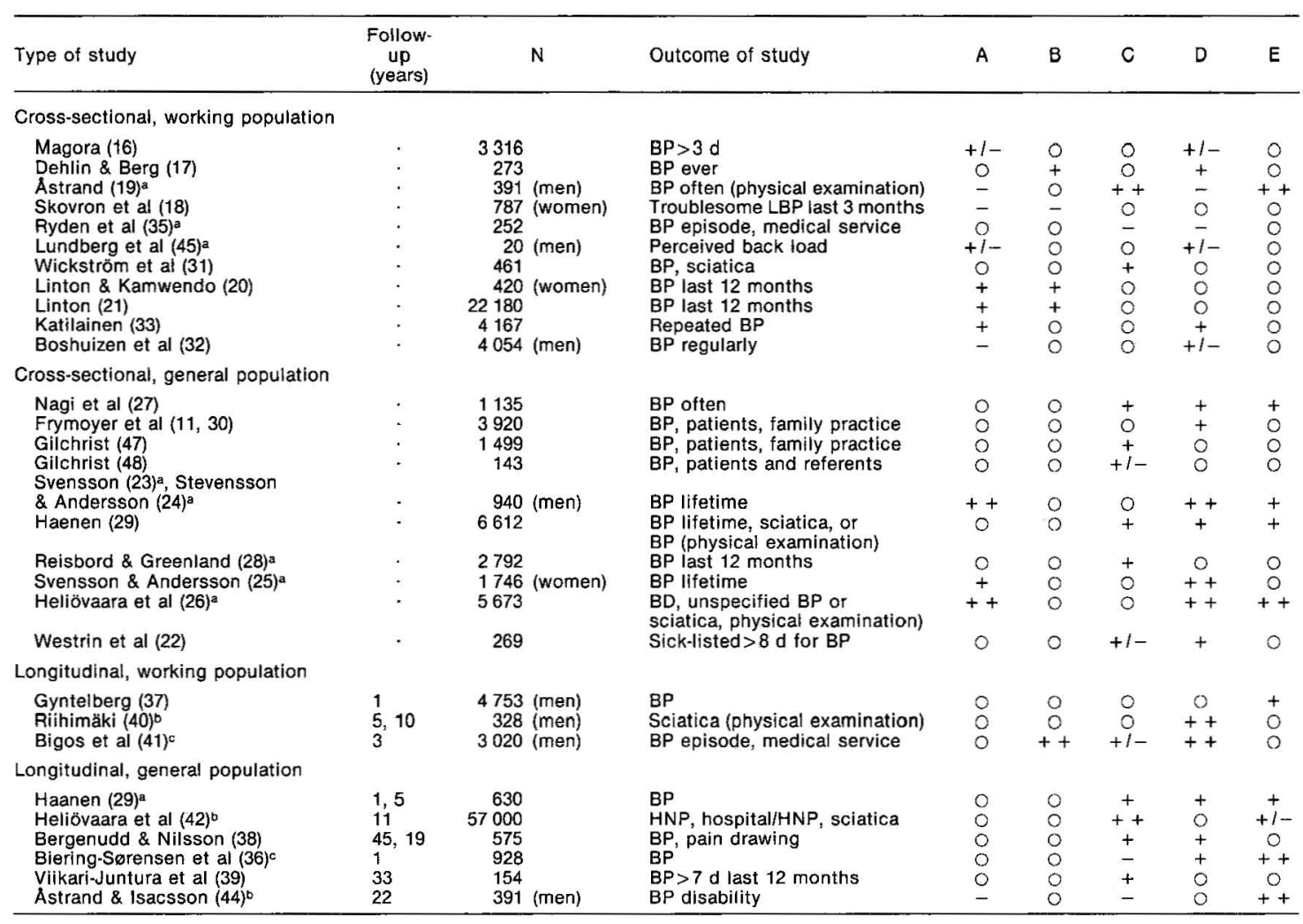

a Adjusted for physical load.

b Adjusted for physical load and base-line musculoskeletal symptoms.

c Adjusted for base-line musculoskeletal symptoms.

cross-sectional studies dealt with work-related variables (22-26). The majority was concerned with the relationship between back trouble and variables such as social class and educational level (27-29), psychological and emotional problems, personality traits $(27-30)$, or parameters of poor health $(24-$ 27). In most of the studies only questionnaires were administered to assess back trouble (16-18, 20, 21, $23-25,27,28,31-33)$. In only three cross-sectional studies was back trouble established after a physical examination $(19,26,29)$. Several cross-sectional studies did not adjust for confounding factors (16, $17,20,27,30,31,34)$ or only for age $(21,29)$. Only eight studies took age and other confounders, including physical load, into consideration $(19,23-$ $26,28,32,35$ ). Information on the strength of the association was presented in about half of the crosssectional studies $(16,19,21,26,28,29,32,33)$. It can be concluded, therefore, that the most informative cross-sectional studies are the multivariate studies investigating the relationship between work-related psychosocial variables and back trouble (other than "Have you ever had back pain?") after adjustment for physical load $(19,26,32)$.
Although the longitudinal studies are definitely more homogeneous in their measurement of dependent and independent variables than the cross-sectional studies, still many differences exist. The duration of follow-up varied from one year $(29,36,37)$ to almost lifelong $(29,38,39)$. The measurement of back pain included self-reported pain in the lower back $(29,36-38)$ or self-reported sciatica $(40)$, episodes registered at the medical service (41), hospital admittance due to herniated disc or sciatica (42, 43 ), or disability due to back pain (44). Except for some of the early studies $(29,37,38)$, potential confounders were dealt with in the design or analysis in all of the longitudinal studies. The emphasis was on personal psychological and emotional problems $(29,36,37,40-42,44)$, stress symptoms $(34,40)$, experienced health $(36,37,42,44)$, or utilization of medical services and demographic variables $(36,37$, 41,42 ). In only a few studies were self-reported work-related psychosocial variables, such as satisfaction with the job $(36,38,41)$, social relations at work (41) and job demands (44), studied. Almost all of the studies also present information on the independent factors measured before the development of symp- 
toms. Strength of the association was presented in most of the longitudinal studies $(29,36,39,40-42,44)$.

Table 3 indicates, for each of the five clusters of table 1 , which of the cross-sectional and longitudinal studies reported a positive association between one of these variables and back trouble and which studied that relationship but did not report a positive association. These associations are discussed next.

Psychosocial factors at work - demands and control. The evidence for a relationship between back trouble and work demands is contradictory. In the cross-sectional studies a positive univariate association was observed between back trouble and selfreported high demands on concentration and possibilities to take a break in some occupations but not in all (16). Other studies also observed such an association, but it did not remain statistically significant after adjustment for other variables (24). A univariate relationship between back pain and high responsibility has been reported for bank employees but not for other occupations (16), and not in another study after adjustment for confounders (19). After adjustment for potential confounders, including physical load and previous back pain, one of the largescale cross-sectional studies reported that a sum score for monotony, time pressure, and worry about mistakes was related to back symptoms established in a physical examination (odds ratio 2.0) (26). A sum score for high time pressure, mental strain, and monotony was also associated with back trouble (questionnaire) in another large-scale cross-sectional study (odds ratio 1.7) (33). However, this association was not adjusted for physical load.
The importance of monotonous work is supported by other researchers, who reported an age-adjusted association between this variable and self-reported back pain (24).

As far as time pressure is concerned, perceived time pressure during work is related to perceived back load during the same period (45). The positive relationship between high time pressure and back symptoms $(26,33,45)$ was not supported by two cross-sectional studies, which analyzed symptoms (32) and clinical signs (19) and also adjusted for physical load and other confounders. Neither did the work-related stressors measured in the study of Åstrand (19) (time pressure and high responsibility) predict future disability due to back disorders in the same population (44). None of the other longitudinal studies investigated the relationship between job demands and back trouble. Only one of these studies investigated the influence of both job demands and control variables (24). These variables were not significantly related to back trouble after adjustment for confounders.

In summary, although contradictory results were reported, the cross-sectional studies yielded some evidence for a relationship between back trouble and aspects of self-reported work demands, in particular monotonous work. The evidence for the effect of working under time pressure is contradictory. The relationship between back trouble and other aspects of job demands (demands on concentration, responsibility, poor career prospects and possibility to take extra breaks) is not clear due to the few data of high quality. In the only longitudinal study that analyzed job demand variables, the variables did not predict future disability due to back disorders.

Table 3 Summary of the associations between neck pain (NP), neck disorders (ND), and shoulder pain (SP) and psychosocial factors at work - demands and control (A), psychosocial factors at work - social support (B), individual characteristics (C), stress symptoms (D), and physical and behavioral health indicators $(\mathrm{E}) .(+=$ positive association, $++=$ positive association after adjustment for confounder, $+I-=$ conflicting data, $-=$ no association, $\mathrm{O}=$ not studied)

\begin{tabular}{|c|c|c|c|c|c|c|c|c|}
\hline Type of study & $\begin{array}{l}\text { Follow- } \\
\text { up }\end{array}$ & $\mathrm{N}$ & Outcome of study & A & B & c & $\mathrm{D}$ & E \\
\hline \multicolumn{9}{|l|}{ Cross-sectional } \\
\hline Ohara et al (57) & . & 848 (women) & $\begin{array}{l}N P \text { in periodic physical } \\
\text { examination }\end{array}$ & + & 0 & 0 & + & 0 \\
\hline Dehlin \& Berg (17) & . & 273 & NP lifetime & - & - & 0 & - & 0 \\
\hline Weste & . & 2537 & NP last 12 months & 0 & 0 & - & 0 & 0 \\
\hline Kvarnström \& Halden (58) & $\cdot$ & 224 & 4 weeks' sick leave due to SP & + & $+1-$ & 0 & + & 0 \\
\hline Tola et al (54) & . & 3232 (men) & $N P>8 d$ last 12 months & - & 0 & - & ++ & 0 \\
\hline Linton \& Kamwendo $(20)$ & . & 420 & NP or SP last 12 months & + & + & 0 & - & 0 \\
\hline Linton (21) & . & 22180 & NP or SP last 12 months & + & + & 0 & 0 & O \\
\hline $\begin{array}{l}\text { Flodmark \& Aase (50) } \\
\text { Mäkelä et al (62) }\end{array}$ & : & $\begin{array}{r}58 \\
7217\end{array}$ & $\begin{array}{l}\text { SP last } 12 \text { months } \\
\text { Chronic neck syndro }\end{array}$ & 0 & 0 & + & 0 & 0 \\
\hline Toomingas et al (63) & . & 358 & $\begin{array}{l}\text { (physical examination) } \\
\text { NP or SP (physical examination) }\end{array}$ & + & $\begin{array}{l}0 \\
+\end{array}$ & $\begin{array}{c}++ \\
0\end{array}$ & $\begin{array}{c}++ \\
0\end{array}$ & $\begin{array}{c}++ \\
0\end{array}$ \\
\hline \multicolumn{9}{|l|}{ Longitudinal } \\
\hline $\begin{array}{l}\text { Bergenudd et al (55) } \\
\text { Hägg et al (49) } \\
\text { Veiersted \& Westgaard }(64)^{b}\end{array}$ & $\begin{array}{l}0 / 35 / 45 \text { years } \\
2 \text { years } \\
0.5 / 1 \text { years }\end{array}$ & $\begin{array}{l}575 \\
83 \text { (women) } \\
30 \text { (men) }\end{array}$ & $\begin{array}{l}S P>24 \mathrm{~h} \text { last } 12 \text { months } \\
\mathrm{NP} \text { or } \mathrm{SP} \text {, physical examination } \\
\mathrm{NP} \text { or } \mathrm{SP} \text { last } 10 \text { weeks }\end{array}$ & $\begin{array}{l}0 \\
0 \\
++\end{array}$ & $\begin{array}{l}0 \\
0 \\
++\end{array}$ & $\begin{array}{l}0 \\
+ \\
\end{array}$ & $\begin{array}{l}+1- \\
+ \\
++ \\
++\end{array}$ & $\begin{array}{l}0 \\
0 \\
0 \\
0\end{array}$ \\
\hline $\begin{array}{l}\text { Takala et al }(56)^{\mathrm{b}} \\
\text { Viikari-Juntura et al }(39)^{\mathrm{a}}\end{array}$ & $\begin{array}{l}3 / 6 / 9 \text { months } \\
1 / 33 \text { years }\end{array}$ & $\begin{array}{l}351 \\
154\end{array}$ & $\begin{array}{l}\text { NP, physical examination } \\
\text { NP or SP }>7 \text { d last } 12 \text { months }\end{array}$ & + & $\stackrel{+}{0}$ & $\begin{array}{l}0 \\
++\end{array}$ & + & $\begin{array}{r}0 \\
++\end{array}$ \\
\hline
\end{tabular}

a Adjusted for physical load.

b Adjusted for physical load and base-line musculoskeletal symptoms. 
Psychosocial factors at work - social support. Low social support by colleagues and superiors without adjustment for confounders was associated with back pain in one cross-sectional study (17). A sum score for the psychosocial work environment (several questions on work content and social relations at work) was positively associated with back trouble (no adjustment for physical load) in two studies $(20,21)$. However, in a similar study no significant association between self-reported poor psychosocial environment and back trouble was observed after adjustment for other variables, including physical load (32). One study even observed a positive association between a good relationship with colleagues and troublesome back pain (18). In a prospective longitudinal study workers with poor social relations at work more frequently reported an episode of back pain to the medical department or filed a claim in the next three years (41). This situation also applied to workers without back pain episodes at the start of follow-up. In the analysis adjustment was made for physical load and other potential confounders. A similar association between poor social support by superiors and episodes of back pain reported to the medical office was previously found in a retrospective study by the same authors (46). They stated that these variables may have been related to the back pain episodes, as well as to the readiness to report them to the medical department or file a claim.

In summary, poor social support at work was associated with the incidence of reported back trouble in the only relevant longitudinal study. The results of the few cross-sectional studies that analyzed the relationship between social support at work and back pain are contradictory. None of the studies on back trouble investigated the effect of demands, control, and support variables simultaneously.

Individual characteristics. Almost all of the crosssectional studies reported a positive association between psychological or emotional problems and selfreported back pain $(19,22,24,25,27,29,30,32$, $42,47,48)$ and "back disorders" diagnosed in a physical examination $(19,26)$. One cross-sectional study reported no association between back episodes registered at the medical service and psychological problems or nervousness (35). Two prospective longitudinal studies found a positive association between certain personality traits, measured with the Minnesota Multiphasic Personality Inventory (MMPI), and episodes of back pain reported to the medical service or insurance company (odds ratio 1.4) (41) and self-reported back pain (odds ratio 2.8) (29). This situation also applied to those respondents not reporting previous back pain at the start of follow-up. Psychosocial distress was also related to hospital admittance due to a herniated disc 10 years later (relative risk 1.7) (42). Neuroticism, however, did not predict disability due to back pain (44), although it showed a strong cross-sectional association (odds ratio 2.8) in the same population (19). In addition neuroticism was not associated with sick leave due to back trouble (22). All of the cross-sectional studies that investigated the influence of type A behavior (competitiveness) on back trouble reported a positive association $(31,49,50)$. However, adjustment for physical load was lacking in these studies. Variables of a different category of individual characteristics such as social class and education are highly intercorrelated and are also correlated with physical demands at work. (See reference 28.) Therefore, a correlation between these variables and musculoskeletal trouble is very likely biased by differences in work-related physical load. Low educational level was associated with back-pain prevalence in several cross-sectional studies $(19,27-29,51)$, but not in all (25). It is remarkable that in one study variables such as low income and little education were related not only to back pain, but also to back abnormalities, established in a physical examination, the latter association being even stronger (19). These variables did not, however, predict later disability due to back problems (44). Two other longitudinal studies (39, 42) tentatively supported a relationship between low educational level or low social class (relative risk 2.5) and back trouble at a later age after some adjustment for physical load during work.

In summary, personality traits and emotional problems are associated with back trouble in both crosssectional studies and longitudinal studies. The results suggest that these variables also predict back trouble for respondents who have not previously experienced back pain. The results, however, were not consistent, and these studies investigated a variety of different dependent variables. Few studies investigated the association with low education or low social class while adjusting for physical load at work. A tentative association between the development of back pain and these variables independent of physical load at work was reported by two longitudinal studies.

Stress symptoms. An association between back trouble and stress symptoms has been reported in several cross-sectional studies $(16,24-27,29,30,32$, 33 ), but not in all (35). Feelings of stress (nervousness, tension, sleeping difficulties) were univariately associated with back trouble in several studies (27, $29,30)$. This association was also significant after adjustment for other risk factors $(24,25,32,33)$ with a reported odds ratio of up to 3.5 (33). Worry about making mistakes (combined in one score with time pressure and monotonous work) was positively associated with "objectively" assessed back pain (26). However, perceived demands and tension or physiological indicators of stress symptoms did not relate 
to simultaneously experienced back load (45). Although several studies reported an association between exhaustion and fatigue and back trouble, this association disappeared after adjustment for other risk factors, including physical load $(24,25,35,36)$. In the longitudinal studies, stress symptoms also increased the risk of symptoms of back pain (29) or sciatica $(43,40)$, although the odds ratios were close to one and not significant for all groups. This situation also applied to those respondents without a history of sciatica or low-back pain before the start of follow-up. In three cross-sectional studies, dissatisfaction with work conditions was significantly associated with self-reported symptoms of the back and sick leave due to back trouble without additional adjustment for confounders $(14,16,17,22,24,29,36$, $38,41)$. However, after adjustment for confounders, a positive association between job dissatisfaction and back trouble was reported by one cross-sectional study (25) and one longitudinal study (41) (odds ratio 1.7), but not by three cross-sectional studies (19, 24,32 ) or one longitudinal study (36).

In summary, the association between back trouble and stress symptoms reported in several cross-sectional studies seems to be tentatively supported by the results of longitudinal studies. This situation applies to self-reported back pain, as well as to signs and symptoms of the back in a physical examination. The results on the relationship between job dissatisfaction and (self-reported) back trouble are not consistent.

Physical and behavioral health indicators. Several cross-sectional studies have reported a positive association between perceived poor health and self-reported $(19,27,29)$ or clinically assessed symptoms of the back (19). This variable also predicted future disability due to back trouble after adjustment for other risk factors (relative risk 3.4) (44). In one of the longitudinal studies, a similar relationship was observed, but it was no longer significant when all of the other variables were taken into account (36). This latter study reported that "rumbling of the stomach" in women showed a significant correlation in a multivariate analysis with back trouble. Epigastric pain proved to be an indicator of first-time occurrence of low-back trouble. The authors stated that these (psychosomatic) symptoms also showed a correlation with back trouble in other studies $(12,13$, 22). Diagnosed respiratory disease was, after adjustment for confounders, associated with self-reported symptoms of the back (51), with clinically assessed unspecified low-back pain (26), and with back trouble after one year (52), but not with back trouble in several other studies $(19,24,36)$. Respiratory disease was also a predictor of hospitalization among men due to a herniated disc and sciatica after 10 years (42). In other studies clinically diagnosed cardiovascular disease was associated with clinically assessed unspecified low-back pain after adjustment for confounders (26), but not with self-reported back trouble $(19,24,36)$.

In summary, in several cross-sectional and longitudinal studies, an association between back trouble (both self-reported and clinically assessed symptoms) and other symptoms of poor health was observed. However, in several cases, the association was not significant after adjustment for other factors. Some studies reported no association at all between back trouble and other indicators of poor health.

\section{Symptoms and disorders of the neck or shoulders}

We found 13 cross-sectional studies and five longitudinal studies on the relationship between psychosocial factors at work or stress and symptoms of the neck or shoulder region (table 3). Four of these studies $(17,20,21,39)$ were also presented earlier because symptoms of both the back and the neck and shoulder region were studied. Most of the studies on neck and shoulder pain present data on self-reported symptoms $(17,20,21,39,33,53-56)$. The other studies are concerned with registered data of periodic physical examinations $(21,57)$, visits to a medical service (53), sick leave (58), or symptoms and signs reported in a physical examination $(49,55,59)$. The analysis of each of the cross-sectional studies concentrated on self-reported work characteristics. In several studies the association between psychosocial factors at work and symptoms of the neck was determined after adjustment for some aspects of postural load $(39,53,54,59)$. The longitudinal studies are very different in design. The association between psychosocial factors and neck and shoulder symptoms are discussed for the same five clusters of table 1 .

Psychosocial factors at work - demands and control. In most of the cross-sectional studies a relationship between several job demand variables and symptoms of the neck and shoulder region are reported (table 3). Only some of the results are conflicting. High responsibility did not have a direct significant influence on the prevalence of shoulder or neck complaints in one study (58). The other studies provided no data on this variable. In only one study was no relation observed between symptoms of the neck or shoulder and the measured job demand variables (17). All of the other cross-sectional studies that investigated this relationship reported a positive association between neck or shoulder pain and job demand variables such as monotonous work, time pressure, poor work content, and high perceived work load $(20,21,58-61)$. Several studies also reported a positive association between the symptoms 
of the neck or shoulder region and a combination of job demand variables $(33,62,63)$ or of job demand and control variables $(20,59-61)$. However, only one cross-sectional study adjusted for physical load (62). Some other studies indicated that the combined effect of variables for psychosocial factors and physical load was larger than the individual effects (21, 61). The reported odds ratio for the relationship between demand variables and neck and shoulder symptoms was 1.2 after adjustment for physical load (62) and 2.7 after adjustment for occupational class only (33). The reported odds ratios for the effect of control at work were $3.3(20)$ and 3.9 (59). However these point estimates of the odds ratios are hard to compare due to the large variation in measurement and treatment in the analysis of these variables. Only two of the longitudinal studies investigated the relationship between job demands (time pressure) and symptoms of the neck and shoulder $(56,64)$. Both reported a positive association, after adjustment for postural load.

In summary, as the majority of the cross-sectional studies reported a relationship between psychosocial variables and symptoms of the neck or shoulders, an association seems likely. Variables such as monotonous work, time pressure, poor work content, and high work load seem to be important. The longitudinal studies that considered this relationship reported a positive relationship between time pressure at work and neck pain.

Psychosocial factors at work - social support. Data on the influence of social support on neck or shoulder symptoms are not consistent. One study observed no effect of social support by colleagues or superiors (17), while others reported a positive association for support by colleagues (20), superiors (21), or a combination of the two (63). In addition, some reported an effect of support by colleagues but not of support by superiors $(59,64)$ or vice versa $(58)$. All of the studies relating psychosocial work environment (combining both demand and support variables) to the prevalence of neck or shoulder pain reported a positive association $(20,21,56)$.

In summary, the sources on support by colleagues or superiors present contradictory data. Yet there is evidence that high demands in combination with these variables, in addition to the influence of physical load at work, increase the prevalence of neck or shoulder symptoms.

Individual characteristics. In one cross-sectional study a relationship was found between emotional problems and symptoms of the neck or shoulders (61). However, depressive episodes in the year be- fore employment were not associated with the development of symptoms of the neck or shoulders in a new job (64). Some results suggest a relationship between the mental resources of people to promote their own health (poor sense of coherence) and neck and shoulder symptoms one year later (39). The two studies on type A behavior in relation to neck or shoulder symptoms reported a positive association $(49,50)$.

Social class was not significantly related to neck and shoulder symptoms after adjustment for physical demands (53). After adjustment for several confounders, including bent and twisted posture, low education was positively related to the prevalence of neck and shoulder symptoms (54). However in the longitudinal studies no clear relationship between low education (at childhood and later on) and symptoms in middle age was established $(38,39)$.

In summary, few studies analyzed the relation between psychological problems and neck or shoulder symptoms, and the variables investigated are diverse (emotional problems, depressive symptoms, and attitude towards own health). The scarce data on neck or shoulder symptoms in relation to social class and education do not suggest a strong relationship.

Stress symptoms. In several cross-sectional studies a positive association between neck trouble and perceived stress or stress symptoms was observed (33, $57,58)$. High perceived stress also predicted development of symptoms in two of the longitudinal studies $(56,64)$. One of the studies reported a stronger relationship of stress symptoms with neck pain than with back pain (relative risk of 2.7 and 1.7 , respectively) (33).

Job dissatisfaction was cross-sectionally related with physical findings of neck and shoulder trouble after adjustment for confounders (54). This relationship was also true for shoulder pain in women, but not in men (55). This variable did not however predict neck or shoulder symptoms one year later (39).

In summary, according to the literature, a relation between stress symptoms or perceived stress at work and symptoms of the neck or shoulders seems likely. No consistent relation between job dissatisfaction and neck or shoulder trouble was observed.

Physical and behavioral health indicators. A relationship with several other nonspecific symptoms of poor health and indicators of health behavior was observed in the only study that concerned this relationship (62). 
Musculoskeletal trouble, locations other than the back or neck and shoulders only

Table 4 summarizes the results of studies with a rather diverse set of end points. Included are studies on the relationship between psychosocial factors and a combination of back, neck, and sometimes upperlimb disorders $(50,65,66)$, all types of musculoskeletal signs or symptoms $(67,68,69)$, and more general muscle pain $(6,66,70-72)$. In the crosssectional study of Ursin et al (70), feelings of anxiety, coping styles, and job stress were analyzed in relation to muscle pain. The other cross-sectional studies have analyzed the relationship between psychosocial factors at work (demands, control, and support variables) and musculoskeletal symptoms (6, $65-69,71,73$ ). Most of these latter studies adjusted for physical load or conducted the analysis within one, homogeneously exposed group (65-68).

The one longitudinal study $(68,74)$ concerned musculoskeletal symptoms determined with a questionnaire and with a physical examination in relation to a sum variable for stress symptoms, perceived psychosocial stress (at work and at home), and social support (both at work and outside work). Table 4 shows the results of the study for each group of variables shown in table 1 .

Psychosocial factors at work - demands and control. In almost all of the studies described in table 4 a positive relation between one or more psychosocial factors at work and musculoskeletal symptoms was reported. The following job demand variables were related to the prevalence of musculoskeletal trouble: monotonous work (71), time pressure (67, $69,73)$, high demands on concentration (65), and high perceived (mental) work load $(6,65,66,69)$. This last relationship was confirmed in the longitu- dinal study of Leino (74). However no significant influence on musculoskeletal trouble was observed for possibilities to take a break (65) and poor work content (69). In contrast to the other studies, time pressure was not significantly related to musculoskeletal trouble in one study (66). In this study, adjustment for physical load considerably decreased the association between time pressure and symptoms of the back, neck, or shoulders. The variables job demands and lack of possibilities to talk were not only related to back, neck, and shoulder disorders, but also to self-reported muscle tension (66). Low job control was positively related to musculoskeletal symptoms in all of the studies $(6,65,66,71)$ except one (69). However the exception reported that only little variation in this variable was present: autonomy was low for most of the workers. Although several of the studies on psychosocial factors and musculoskeletal trouble analyzed the influence of both job demand and support or control variables, each of these variables was treated as an independent variable, and no information on the interaction between them was presented.

In summary, monotonous work, time pressure, and high perceived work load each seem to be related to musculoskeletal problems. Almost all of the studies stressed the importance of little control over one's job.

Psychosocial factors at work - social support. Although most studies have observed a relationship between musculoskeletal trouble and poor social support at work by colleagues $(65,69,71)$, this relationship was not consistent in all studies. Two reported no association between social support at work and back, neck, and shoulder symptoms and symptoms of other joints, regardless of adjustment for physi-

Table 4. Summary of the associations between musculoskeletal disease not specified and psychosocial factors at work demands and control (A), psychosocial factors at work - social support (B), individual characteristics (C), stress symptoms (D), physical and behavioral health indicators $(E) .(+=$ positive association, $++=$ positive association after adjustment for confounders,$+1-=$ conflicting data, $-=$ no association; $O=$ not studied, NP = neck pain, BP = back pain, LBP $=$ low-back pain, $\mathrm{SP}=$ shoulder pain)

\begin{tabular}{|c|c|c|c|c|c|c|c|c|}
\hline Type of study & $\begin{array}{l}\text { Follow-up } \\
\text { (years) }\end{array}$ & $\mathrm{N}$ & Outcome of study & A & $\mathrm{B}$ & $\mathrm{C}$ & $D$ & $E$ \\
\hline \multicolumn{9}{|l|}{ Cross-sectional } \\
\hline $\begin{array}{l}\text { Sauter et al (65) } \\
\text { Karasek et al }(6) \\
\text { Pot et al }(69) \\
\text { Ursin et al (70) } \\
\text { Kompier }(67)^{\mathrm{a}} \\
\text { Hopkins (71) } \\
\text { Magni et al (72) }\end{array}$ & $\begin{array}{l}\dot{.} \\
\dot{.} \\
\dot{.} \\
\dot{.}\end{array}$ & $\begin{array}{r}248 \\
8700 \\
222 \\
474 \\
158 \\
291 \\
3023\end{array}$ & $\begin{array}{l}\text { NP or BP } \\
\text { Musculoskeletal ache } \\
\text { Often musculoskeletal pain } \\
\text { Muscular pain } \\
\text { Musculoskeletal pain last } 12 \text { months } \\
\text { Muscular pain last } 6 \text { months } \\
\text { Musculoskeletal trouble }>1 \text { month } \\
\text { during last } 12 \text { months }\end{array}$ & $\begin{array}{l}++ \\
+ \\
+1 \\
0 \\
++ \\
+ \\
0\end{array}$ & $\begin{array}{c}0 \\
+1- \\
+ \\
0 \\
++ \\
+ \\
0\end{array}$ & $\begin{array}{l}0 \\
0 \\
0 \\
+ \\
++ \\
0 \\
+\end{array}$ & $\begin{array}{l}0 \\
0 \\
0 \\
+1- \\
0 \\
+ \\
0\end{array}$ & $\begin{array}{l}0 \\
0 \\
0 \\
0 \\
++ \\
0 \\
0\end{array}$ \\
\hline $\begin{array}{l}\text { Smulders }(73)^{\mathrm{a}} \\
\text { Theorell et al }(66)^{\mathrm{a}}\end{array}$ & $\dot{\cdot}$ & $\begin{array}{r}9000 \\
207\end{array}$ & $\begin{array}{l}\text { LBP + leg or feet, pain regularly } \\
\text { Frequent } B P, N P \text { or } S P \text {, joint pain }\end{array}$ & $\begin{array}{l}++ \\
++\end{array}$ & $+\bar{l}-$ & $\begin{array}{l}0 \\
+\end{array}$ & $\begin{array}{l}0 \\
++\end{array}$ & $\begin{array}{l}0 \\
++\end{array}$ \\
\hline \multicolumn{9}{|l|}{ Longitudinal } \\
\hline Leino $(74)^{b}$, Leino \& Lyyra $(68)^{b}$ & 10 & 902 & $\begin{array}{l}\text { All musculoskeletal symptoms and } \\
\text { signs (questionnaire and physical } \\
\text { examination) }\end{array}$ & ++ & $+1-$ & $\mathrm{O}$ & ++ & 0 \\
\hline
\end{tabular}

a Adjusted for physical load.

- Adjusted for physical load and base-line musculoskeletal symptoms. 
cal load $(6,66)$. Poor social support by superiors was also positively related to musculoskeletal problems in most studies $(66,67,69,71)$, but not in all (73), or only among women and not among men (6). For blue-collar women, a significant cross-sectional association between poor social support and base-line musculoskeletal findings was reported in a longitudinal study (68). Poor social support was also associated with musculoskeletal symptoms and signs during the follow-up, but this association was not significant.

In summary, most of the cross-sectional studies reported that high job demands, low control, and poor social support were associated with self-reported musculoskeletal trouble. This was also the situation for those studies that adjusted for physical load. However the association did not consistently apply to all of the variables or all of the respondents.

Individual characteristics. Anxiety and depressive symptoms were positively related to musculoskeletal symptoms (70). An association between type A behavior and musculoskeletal trouble was also reported $(50,66)$. Only one study analyzed the association between low income (low social class) and musculoskeletal trouble, and it reported a positive association (6).

In summary, a relationship between psychological and emotional problems and musculoskeletal symptoms was reported in the few studies that investigated this relationship.

Stress symptoms. In one of the cross-sectional studies a positive association between various stress symptoms (anger, worry, fatigue, sleep disturbances, loss of appetite) and self-reported muscle tension was reported (66). Muscle tension was in turn associated with back, neck, and shoulder symptoms, as were other types of tension (breath tension, chewing tension, and type A tension), but not several physiological parameters (systolic blood pressure and plasma cortisol). No direct associations between stress symptoms and back, neck, and shoulder symptoms were reported in this study. Perception of the work environment as stressful was related to symptoms in one cross-sectional study (71) but not in another (70).

Leino (74) reported that a sum score for self-reported stress symptoms was related to self-reported base-line musculoskeletal symptoms and clinical findings. In addition, the base-line score for stress symptoms was related to the clinical findings after 10 years of follow-up. On the other hand, the baseline musculoskeletal symptoms were also related to stress symptoms after 10 years of follow-up. This re- lationship was not, however, equally consistent for all of the groups as the reverse relationship was. Thus this study presented some evidence that stress symptoms were not only related to self-reported musculoskeletal complaints, but also to adverse changes in clinical symptoms and signs after 10 years of followup, also for those respondents without musculoskeletal symptoms at the start of the study. It also showed that, for perceived psychosocial stress, a sum score that contains items on work- and nonwork-related psychosocial factors (overstrained by work, pressed work pace, mentally strenuous work, financial problems, trouble with kids or relatives, fear of making mistakes) was cross-sectionally related to musculoskeletal symptoms and signs among men only in the base-line measurements (68). However the initial perceived stress did not predict symptoms after 10 years of follow-up but did predict musculoskeletal findings among blue-collar workers.

Only one study analyzed the association between job dissatisfaction and musculoskeletal complaints and reported a positive association (71). In the study of Karasek et al (6), job (dis)satisfaction was treated as a dependent variable, and no information on its association with musculoskeletal trouble was presented.

In summary, a relationship between stress symptoms and the development or exacerbation of musculoskeletal symptoms established by interview and physical examination seems likely. Muscle tension may be an intermediate of this process. Only few data are available on the relation between job satisfaction and musculoskeletal trouble.

Physical and behavioral health indicators. Only two studies reported on the association between other health effects and musculoskeletal disorders. Both poor health in general (67) and psychosomatic symptoms such as gastrointestinal trouble were related to musculoskeletal trouble (66).

\section{Discussion}

\section{Quality of the studies}

We found 44 cross-sectional and 15 longitudinal studies reporting empirical results on the subject of this review. Only 29 cross-sectional and three longitudinal studies specifically analyzed the influence of psychosocial factors at work. The other studies dealt with the relationship between factors such as stress symptoms or psychological problems and musculoskeletal symptoms. Not all of the reviewed studies were of high quality. Only 22 adjusted in some way for physical load. In nine the outcome was established after a physical examination. 


\section{Summary of the results for all sites combined}

As the presented results do not appear to be essentially different for each musculoskeletal site, table 5 presents a summary of the relationships presented in the Results section, when the results for back, neck and shoulder, and general musculoskeletal problems are combined. Due to several shortcomings, to be discussed later on, the reviewed studies do not present conclusive evidence. Nevertheless, a qualitative summary evaluation of the evidence for the various relationships is presented in the following.

Psychological factors at work - demands and control. Although the results on time pressure are conflicting, the epidemiologic studies support a relationship between monotonous work, perceived work load, and work under time pressure on one hand and musculoskeletal trouble on the other. The studies dealing with neck or shoulder symptoms or muscle pain emphasize the importance of control at work.

Psychosocial factors at work - social support. Several studies, on both back disorders and musculoskeletal trouble, lend support to the relevance of social support by colleagues at work, although the results are not consistent. In addition, a combination of job demands and support was consistently related to musculoskeletal trouble.

Individual characteristics. Several emotional and psychological problems are related to musculoskeletal trouble. In the cross-sectional studies these problems were either a cause of musculoskeletal symptoms or a result of them. Two longitudinal studies showed that some personality traits predict musculoskeletal trouble, whereas two others did not support this finding. Therefore the role of these varia-

Table 5. Summary of the epidemiologic evidence for the relationship between psychosocial factors, personal characteristics, stress, and musculoskeletal disease $(+=$ positive evidence for an association, $-=$ association absent, $+/-=$ conflicting data, $?=$ too little information, BP = back pain, NP/SP = neck or shoulder pain, MP = symptoms of the musculoskeletal system, no location specified (neck or shoulder and back or all musculoskeletal sites))

\begin{tabular}{|c|c|c|c|c|c|c|}
\hline & $\begin{array}{l}\text { Cross- } \\
\text { sectional } \\
\text { studies } \\
(\mathrm{N})\end{array}$ & $\begin{array}{l}\text { Longitu- } \\
\text { dinal } \\
\text { studies } \\
\text { (N) }\end{array}$ & $\mathrm{BP}$ & NPISP & MP & Total \\
\hline Psychosocial factors at work - demands and control & 28 & 2 & $+1-$ & $?$ & + & + \\
\hline Monotonous work & & & + & + & + & + \\
\hline Time pressure & & & $+1-$ & + & + & + \\
\hline High concentration & & & - & $?$ & $?$ & $?$ \\
\hline High responsibility & & & - & ? & - & $?$ \\
\hline Poor work content & & & + & + & $?$ & $+1-$ \\
\hline High work load & & & $?$ & $+1-$ & + & + \\
\hline Lack of clarity & & & $?$ & $?$ & - & $?$ \\
\hline Few opportunities to take breaks & & & - & $?$ & - & - \\
\hline Low control, autonomy & & & $?$ & $\dot{?}$ & + & + \\
\hline Psychosocial factors at work - social support & 15 & 2 & + & $+1-$ & + & + \\
\hline $\begin{array}{l}\text { Poor social support by colleagues } \\
\text { Poor social support by superiors } \\
\text { Demand and support variables combined }\end{array}$ & & & $\begin{array}{l}+ \\
? \\
+\end{array}$ & $\begin{array}{l}+1- \\
+1- \\
+\end{array}$ & $\begin{array}{l}+ \\
+ \\
?\end{array}$ & $\begin{array}{l}+ \\
+1- \\
+\end{array}$ \\
\hline Individual characteristics & 15 & 9 & $+1-$ & $?$ & $?$ & $?$ \\
\hline Neuroticism & & & $+1-$ & $?$ & $?$ & $?$ \\
\hline Type A behavior & & & + & + & + & + \\
\hline Extrovert personality & & & $?$ & - & $?$ & $?$ \\
\hline Depression & & & $+i-$ & $?$ & ? & $?$ \\
\hline Coping styles & & & - & $?$ & $?$ & $?$ \\
\hline Attitude towards own health & & & $+1-$ & $?$ & + & + \\
\hline Low social class & & & $+1-$ & - & $?$ & - \\
\hline Low educational level & & & $+1-$ & $+1-$ & $?$ & $+1-$ \\
\hline Stress symptoms & 24 & 8 & + & + & + & + \\
\hline $\begin{array}{l}\text { Worry, tension, anxiety, nervousness } \\
\text { Physical stress symptoms } \\
\text { Tiredness and exhaustion } \\
\text { High perceived work stress } \\
\text { Low job satisfaction } \\
\text { Physiological parameters }\end{array}$ & & & $\begin{array}{l}+ \\
+ \\
+1- \\
+ \\
+1- \\
?\end{array}$ & $\begin{array}{l}+ \\
? \\
? \\
+ \\
+1- \\
?\end{array}$ & $\begin{array}{l}+ \\
? \\
? \\
+ \\
? \\
?\end{array}$ & $\begin{array}{r}+ \\
? \\
+1- \\
+ \\
+1- \\
?\end{array}$ \\
\hline Physical and behavioral health indicators & 8 & 8 & + & $?$ & $?$ & + \\
\hline $\begin{array}{l}\text { Poor physical health } \\
\text { Respiratory disease or cough } \\
\text { Stomach trouble } \\
\text { Cardiovascular disease } \\
\text { Headache } \\
\text { Use of medication } \\
\text { Use of medical services }\end{array}$ & & & $\begin{array}{l}+ \\
+ \\
+ \\
+1- \\
+1- \\
+ \\
+\end{array}$ & $\begin{array}{l}? \\
? \\
? \\
? \\
? \\
? \\
?\end{array}$ & $\begin{array}{l}? \\
? \\
? \\
? \\
? \\
? \\
?\end{array}$ & $\begin{array}{c}+ \\
+ \\
+ \\
+1- \\
+1- \\
+ \\
+\end{array}$ \\
\hline
\end{tabular}


bles in the development of musculoskeletal trouble is not clear. The reviewed studies do not support a strong predictive effect of low social class or poor education on the development of musculoskeletal pain when physical load is controlled for.

Stress symptoms. Some of the studies that measured stress before the onset of symptoms and adjusted for other risk factors point to a role of stress in the development of musculoskeletal trouble.

Physical and behavioral indicators of health. The data suggest that back and neck trouble are often accompanied by other symptoms of poor health.

Several of the reported results were conflicting. The differences may be due to the heterogeneous character of the studies with respect to the measured independent and dependent variables.

\section{Independent variables}

Many different methods were employed to measure the independent variables. This statement applies to the measurement of psychosocial factors at work, stress symptoms, and personal characteristics. In addition the variables included in the category personal characteristics, for example, emotional problems and personality traits, are very diverse. It is therefore difficult to draw any overall conclusions.

\section{Confounding variables}

At the workplace a high correlation often exists between psychosocial factors and physical load. In assessing the importance of psychosocial variables for musculoskeletal symptoms, it is important to adjust for physical load. Many of the reviewed studies failed to do so. All of the studies that applied some adjustment for physical load, except one (45), relied on self-reports for the assessment of physical load. Several publications have shown that the validity of self-reported physical exposure is questionable (75, 76). In several studies within a specific occupation (eg, operators of visual display units or health care workers) high mutual correlations between self-reported psychosocial factors and physical load can make it difficult to disentangle the effect of each of these variables. Due to the limited assessment of physical load, none of the reviewed studies presents conclusive evidence of the role of work-related psychosocial variables or stress symptoms in musculoskeletal disease.

\section{Outcome}

Few studies conducted a physical examination for the assessment of the outcome variable. When both independent and dependent variables are self-reports, a relationship between these variables can arise from general dissatisfaction or readiness to report complaints. The same is true for the relationship between self-reported work-related psychosocial variables and reported claims for disability (41). Therefore the relationship between self-reported psychosocial factors and self-reported musculoskeletal symptoms or claims is expected to be stronger than the relationship between these variables and symptoms and signs established in a physical examination. Several studies not only showed an association between these variables and self-reported musculoskeletal complaints, but also between these variables and physical findings $(19,63)$. Toomingas et al (63) reported a similar association between job demands and selfreported symptoms of the neck or shoulder region (odds ratio 1.5) and tenderness by palpation (odds ratio 1.9). This association applied even more strongly to the relationships between these outcome variables and social support at work (odds ratios 1.7 and 5.0 , respectively). Some longitudinal studies have also reported that psychosocial factors and low job satisfaction predict future musculoskeletal problems after adjustment for back trouble at the start of follow-up. These data showed that not all of the reported results can be fully attributed to spurious associations due to the fact that most of the studies relied on self-reports for both the dependent and independent variables.

It can be hypothesized that psychosocial factors, stress symptoms, and individual characteristics are more strongly related to nonspecified back pain than to back disorders, such as a herniated disc. In the study of Heliövaara et al (26) the odds ratio for the relationship between psychosocial factors and unspecified low-back pain (odds ratio 1.4) was unexpectedly lower than that for the relationship between psychosocial factors and self-reported sciatica (odds ratio 2.0 ).

\section{Specificity of the findings for each musculoskeletal site}

Some of the studies reported odds ratios of similar magnitude for the relationships between musculoskeletal symptoms of the different body regions and psychosocial factors. The cross-sectional study of Katilainen (33) showed an odds ratio of 2.7 for the relationship between a sum score for mental load (distractions, tight time schedule, mental strain, monotony, and workpace) and neck and shoulder symptoms and 1.7 for back symptoms.

Recently, strong associations have been reported between back symptoms or neck symptoms and osteoarthritis of the knee, hip, or hand (odds ratio of 5.3 and 1.6 , respectively) $(26,62)$. In the study of Mäkelä et al (62) a high association between symptoms of the neck and low back was also reported (odds ratio 4.3). This high association between several musculoskeletal symptoms may have been due 
to the perception or reporting of symptoms, but it may also have been an indication of exposure to shared risk factors or of common etiologic factors.

\section{Physical load versus psychosocial factors}

Only few studies present quantitative data on the relative importance of physical load and psychosocial load to musculoskeletal trouble $(4,26,33,64,62)$. Heliövaara et al (26) reported an odds ratio of 2.5 for the relationship between unspecified low-back pain and a sum score for physical load (highest category versus lowest category) and an odds ratio of 1.4 for a sum score for psychosocial factors. For selfreported sciatica the odds ratios were almost similar (1.9 and 2.0, respectively). For the same population Mäkelä et al (62) reported similar odds ratios of 1.3 and 1.2 for the relationship between neck or shoulder symptoms and a sum score for physical load and psychosocial factors (odds ratios computed for each additional score level). For a comparable population odds ratios were reported of similar magnitude (odds ratios around 2) for physical load and psychosocial factors in relation to neck symptoms (33). With respect to back pain the odds ratios for physical load and psychosocial factors were 2.3 and 1.7, respectively. Veiersted \& Westgaard (64) observed that both strenuous posture and psychosocial factors were risk factors for trapezius myalgia, with point estimates of the relative risks of around 10 for both factors. (Due to small numbers these estimates are imprecise.) These data tentatively suggest that for neck and shoulder symptoms similar risk estimates were reported for both physical load and psychosocial factors, whereas, for back symptoms, the risk estimate for the physical load tended to be slightly higher than for psychosocial factors.

\section{Nonwork psychosocial factors}

The relationships between psychosocial factors outside work and musculoskeletal symptoms are not included in this review. If these factors are of major importance, the conclusions based on work-related factors alone may not be correct. In a more extensive report on the subject (15) we concluded that studies investigating the relationships between musculoskeletal symptoms and psychosocial factors outside the work environment, such as life events (29, $30)$ or social support in the family $(19,35,38,41$, 59,37 , did not report a strong relationship between these factors and musculoskeletal symptoms.

\section{Chance findings}

Conflicting data can also be due to chance. In several studies many associations were tested, and, therefore, there was the possibility that several would turn out to be significant, if only due to chance. How- ever it should be noted that only few studies showed associations between musculoskeletal trouble and psychosocial variables in the direction opposite to that expected.

\section{Discussion of the results in view of the hypothesized mechanisms}

In the following discussion the relationships presented in the Results section are presented according to the hypothesized associations in figure 1 . These associations are (i) stressors at work directly influence mechanical load and (ii) psychosocial factors at work (demands, control, and social support), modified by individual characteristics, increase workrelated stress, which may increase muscle tone and lead to the development of musculoskeletal symptoms or increase the musculoskeletal symptoms due to some unknown physiological mechanism and which may increase the perception of musculoskeletal symptoms and thus prolong or intensify these symptoms or increase symptoms of poor health in general, including musculoskeletal symptoms.

When all of the reported data are combined, it is concluded that monotonous work, time pressure, and perceived high work load each show a positive relation with musculoskeletal trouble, although such a relationship was not observed consistently in all of the studies. Part or all of this association can be attributed to the high mechanical load associated with these variables. This conclusion has been illustrated by Theorell et al (66), who showed that the strength of the association between perceived time pressure and symptoms of the back, neck, or shoulder decreased considerably after adjustment for physical load. In several studies, however, a statistically significant odds ratio remained even after adjustment for physical load. This difference can be due to residual confounding, since physical load is hard to measure accurately, or it may indicate an effect of these demand variables that is additional to the associated mechanical load. Some of the other job demand variables that are probably less strongly related to mechanical load, such as lack of clarity or high demands on concentration, showed no clear association with musculoskeletal symptoms, but few of the studies analyzed the role of these variables. However, the positive association between low control, poor social support by colleagues, and combinations of these variables on one hand and musculoskeletal trouble on the other seems to indicate that an association between (some) psychosocial factors independent of increased mechanical load seems likely.

It was hypothesized that perceived stress or stress symptoms are an intermediate in the relationship between psychosocial factors at work and the development of musculoskeletal symptoms. Before it can be determined whether stress symptoms are a result or a cause of musculoskeletal pain, stress symptoms 
should be measured before the onset of musculoskeletal symptoms. A few of the studies that both did so and adjusted for other factors provide some evidence for the role of stress in the development of musculoskeletal trouble. The evidence supporting the assumption that stress predicts musculoskeletal symptoms is slightly more convincing than that for the opposite relationship. Although both relationships are probably true. One study (33) showed that both psychosocial factors and stress symptoms were related to back (odds ratio 1.7 and 3.5, respectively) and neck or shoulder trouble (odds ratio 2.7 and 4.2, respectively). If the relationship between psychosocial factors and back or neck or shoulder trouble was adjusted for the stress symptom score, the odds ratios were 1.7 and 2.0 and remained statistically significant. This result shows that stress symptoms are not necessarily an intermediate in the relationship between psychosocial factors at work and back trouble, although the stress symptom score in itself was strongly associated with back trouble.

Only one of the epidemiologic studies (66) provided data on the possible intermediate role of (chronic) muscle tension. In this study several selfreported stress symptoms were related to self-reported muscle tension. Muscle tension in turn was related to back, neck, or shoulder symptoms. No information has been presented on the direct association between stress symptoms and symptoms of the back, neck, or shoulders. Some of the psychosocial factors (high demands and lack of opportunities to talk) were directly associated with muscle tension. The stress variables were also associated with other types of self-reported tension (eg, breath tension). These types of tension were also related to musculoskeletal symptoms. Several experimental studies have previously shown that muscle tension increases with increasing perceived stress. The only other study that tested the relationship between physiological parameters and musculoskeletal symptoms observed no positive association (45).

It cannot be inferred from the presented data whether the relationship between stress symptoms and musculoskeletal trouble is the result of an increased general perception of symptoms or a specific (physiological) mechanism. Most of the studies that analyzed the relationship between other physical and behavioral health indicators and back trouble reported a positive association. It is remarkable however that several of these studies report a significant univariate association that was no longer significant after other variables were included, for example, stress symptoms and individual characteristics, in a multivariate model. Some studies (see, eg, reference 44) however lend support to the hypothesis that poor health is associated with and may predict back and neck trouble. This finding seems to suggest that stress influences the perception of both musculoskeletal symptoms and symptoms coming from other parts of the body. It does not necessarily mean how- ever that increased musculoskeletal symptoms are due to increased perception. This correlation between stress and indicators of poor health may also be partly due to shared risk factors for both stress and musculoskeletal trouble (eg, age). In addition, in some cases, medical explanations may account for the relationship. For example, increased spinal pressure due to chronic cough may be responsible for the association between frequent coughing and back pain.

Additional data are needed for more information on the plausibility of the various explanations for the empirical associations reported in the literature.

\section{Recommendations}

In future research on the relationship between psychosocial variables and musculoskeletal disease, it seems important to assess (i) the psychosocial factors at work through observation or with neutral questions, (ii) the perception of workers concerning these variables, (iii) the self-reported stress and stress symptoms, special attention being given to musclular tension, (iv) mechanical load by measurement, and (v) musculoskeletal symptoms (duration and type of symptoms) from self-reports and musculoskeletal symptoms and signs from physical examinations.

With respect to the psychosocial factors the variables from the job demands and job decision latitude model for work stress (demands, control, and social support) should receive special attention. Epidemiologic research should attempt to assess the relevance of all these variables in relation to each other. Longitudinal studies may provide information on the temporal relation and are therefore of primary importance. Moreover, in study design and analysis, a clear distinction between risk factors for the development of musculoskeletal trouble, the persistence of symptoms, and the prediction of sick leave and disability appears to be important.

Thus future studies on psychosocial variables related to musculoskeletal trouble should ideally be longitudinal, directed towards the analysis of the development or persistence of symptoms or pathology (disability), and pay attention to the independent effect and interaction between mechanical load, psychosocial factors at work, and stress symptoms. Such studies would provide society with better tools to set priorities in the prevention of work-related musculoskeletal disease and job (re)design.

\section{Acknowledgments}

The preparation of this paper was partly supported by The Ontario Workers Compensation Institute, Toronto, Canada.

This paper received the Irma Åstrand Award, presented at the International Scientific Conference on Prevention of Work-Related Musculoskeletal Disorders PREMUS, which was held in Stockholm on 12-14 May 1992. 


\section{References}

1. Haldeman S. Presidential address, North American Spine Society: failure of the pathology model to predict back pain. Spine 1991;15:718-24.

2. Hildebrandt VH. A review of epidemiological research on risk factors of low back pain. In: Buckle $\mathrm{P}$, ed. Musculoskeletal disorders at work: proceedings of a conference held at the University of Surrey, Guildford, 13-15 April 1987. London (etc): Taylor \& Francis, 1987:9-16.

3. Hagberg M, Wegman DH. Prevalence rates and odds ratios of shoulder neck diseases in different occupational groups. $\mathrm{Br} \mathrm{J}$ Ind Med 1987;44:602-10.

4. Riihimäki H. Low-back pain, its origin and risk indicators. Scand J Work Environ Health 1991;17:81-90.

5. Walsh K, Varnes N, Osmond C, Styles R, Coggon D. Occupational causes of low-back pain. Scand J Work Environ Health 1989;15:54-9.

6. Karasek R, Gardell B, Lindell J. Work and non-work correlates of illness and behaviour in male and female Swedish white collar workers. J Occup Behav 1987;8: $187-207$.

7. Theorell T, Lind E, Floderus B. The relationship of disturbing life changes and emotions to the early development of myocardial infarction and other serious illnesses. Int J Epidemiol 1975;4:281.

8. Cohen F. Stress, emotion, and illness. In: Temoshok L, van Dyke C, Zepans LS, ed Emotions in health and illness: theoretical and research foundations. Orlando, FL: Grune and Stratton, 1983:31-5.

9. Love AW, Peck CL. The MMPI and psychological factors in chronic low back pain: a review. Pain 1987;28:1-12.

10. Romano JM, Turner JA. Chronic pain and depression: does the evidence support a relationship. Psychol Bull 1985;97:18-34.

11. Frymoyer JW, Cats-Baril W. Predictors of low back pain disability. Clin Orthop 1987;221:89-98.

12. Bergquist-Uliman M, Larsson U. Acute low back pain in industry: a controlled prospective study with special reference to therapy and confounding factors. Acta Orthop Scand Suppl 1977;170:41-109.

13. Vällfors B, Hansson J, Magnusson L, Nachemson A. The acute back patient and his working environment. Scand J Rehabil Med 1985; suppl 11:27-39.

14. Bergenudd $\mathrm{H}$, Johnell $\mathrm{O}$. Somatic versus nonsomatic shoulder and back pain experience in middle age in relation to body build, physical fitness, bone mineral content, gamma-glutamyl transferase, occupational workload, and psychosocial factors. Spine 1991;16(9): $1051-5$

15. Bongers PM, de Winter CR. Psychosocial factors and musculoskeletal disease: a review of the literature. Leiden: TNO Institute of Preventive Health Care, 1992:28.

16. Magora A. Investigation of the relation between low back pain and occupation (V. psychological aspects). Scand J Rehabil Med 1973;5:191-6.

17. Dehlin O, Berg S. Back symptoms and psychological perception of work: a study among nursing aides in a geriatric hospital. Scand J Rehabil Med 1977;9:615

18. Skovron ML, Mulvihill MN, Sterling RC, Nordin M, Tougas G, Gallagher M, et al. Work organisation and low back pain in nursing personnel. Ergonomics 1987; $30(2): 359-66$

19. Åstrand N-E. Medical, psychological, and social factors associated with back abnormalities and self reported back pain: a cross sectional study of male employees in a Swedish pulp and paper industry. Br J Ind Med 1987:44:327-36.

20. Linton SJ, Kamwendo K. Risk factors in the psychosocial work environment for neck and shoulder pain in secretaries. J Occup Med 1989;31(7):609-13.
21. Linton SJ. Risk factors for neck and back pain in a working population in Sweden. Work Stress 1990; 4(1):41-9.

22. Westrin CG, Hirsch C, Lindegärd B. The personality of the back patient. Clin Orthop 1972;87:209-16.

23. Svensson H-O. Low back pain in forty to forty-seven year old men: II. socio-economic factors and previous sickness absence. Scand J Rehabil Med 1982;14:5560.

24. Svensson H-O, Andersson GBJ. Low-back pain in 40to 47-year old men: work history and work environment factors. Spine 1983;8:272-6.

25. Svensson H-O, Andersson GBJ. The relationship of low-back pain, work history, work environment, and stress; a retrospective cross-sectional study of 38- to 64-year-old women. Spine 1989;14(5):517-22.

26. Heliövaara $M$, Mäkelä $M$, Knekt $P$, Impivaara $O$, Aromaa A. Determinants of sciatica and low-back pain. Spine 1991;16(6):608-14.

27. Nagi SZ, Riley LE, Newby LG. A social epidemiology of back pain in a general population. J Chronic Dis 1973;26:769-79.

28. Reisbord LS, Greenland S. Factors associated with self-reported back-pain prevalence: a population-based study. J Chronic Dis 1985;38(8):691-702.

29. Haanen HCM. Een epidemiologisch onderzoek naar lage-rugpijn [An epidemiological survey on low back pain] [dissertation]. Rotterdam: Erasmus University, 1984.

30. Frymoyer JW, Pope MH, Costanza MC, Rosen JC, Goggin JE, Wilder DG. Epidemiologic studies of lowback pain. Spine 1980;5(5):419-23.

31. Wickström G, Pentti J, Hyytiänen K, Uutela A. Type A behaviour and back pain. Work Stress 1989;3(2): $203-7$.

32. Boshuizen HC, Verbeek JHAM, Broersen JPJ, Weel ANH. Do smokers get more back pain? Spine. In press.

33. Katilainen R. Labour office interview survey and survey of working conditions 1977. Helsinki: Central Statistical Office, 1978. (Cited in: Leino P, Heiskanen T, Hasan J. On specificity of musculoskeletal symptoms: a biosomatic excursion. Submitted to: Sebeok A, Umiker-Sebeok J, ed. The semiotic web, yearbook 1991.)

34. Frymoyer JW, Pope MH, Clements JH, Wilder DG, McPherson B, Ashikaga T. Risk factors in low-back pain. J Bone Joint Surg 1983;65-A(2):213-8.

35. Ryden LA, Molgaard CA, Bobbitt S, Conway J. Occupational low-back injury in a hospital employee population: an epidemiologic analysis of multiple risk factors of a high-risk occupational group. Spine 1989; 14(3):315-20.

36. Biering-Sørensen F, Thomsen CE, Hilden J. Risk indicators for low back trouble. Scand J Rehabil Med 1989;21:151-7.

37. Gyntelberg F. One year incidence of low back pain among male residents of Copenhagen aged $40-59$. Dan Med Bull 1974;21(1):30-6.

38. Bergenudd $H$, Nilsson $B$. Back pain in middle age: occupational workload and psychologic factors: an epidemiologic survey. Spine 1988;13(1):58-60.

39. Viikari-Juntura E, Vuori J, Silverstein BA, Kalimo R, Kuosma E, Videman T, et al. A life-long prospective study on the role of psychosocial factors in neck-shoulder and low-back pain. Spine 1991;16(9):1056-61.

40. Riihimäki $H$, Wickström $G$, Hänninen $K$, Luopajärvi T. Predictors of sciatic pain among concrete reinforcement workers and house painters: a five year followup. Scand J Work Environ Health 1989;15:415-23.

41. Bigos SJ, Battié MC, Spengler DM, Fisher LD, Fordyce WE, Hansson TJ, et al. A prospective study of work perceptions and psychosocial factors affecting the report of back injury. Spine 1991;16(1):1-6.

42. Heliövaara $M$, Knekt $P$, Aromaa A. Incidence and risk factors of herniated lumbar intervertebral disc or sci- 
atica leading to hospitalization. J Chronic Dis $1987 ; 40(3): 251-8$.

43. Heliövaara M. Occupation and risk of herniated lumbar intervertebral disc or sciatica leading to hospitalization. J Chronic Dis 1987;40(3):259-64.

44. Åstrand N-E, Isacsson S-O. Back pain, back abnormalities, and competing medical, psychological, and social factors as predictors of sick leave, early retirement, labour turnover, and mortality: a 22 year follow-up of male employees in a Swedish pulp and paper company. Br J Ind Med 1988;45:387—95.

45. Lundberg U, Granqvist M, Hansson T, Magnusson $M$, Wallin L. Psychological and physiological stress responses during repetitive work at an assembly line. Work Stress 1989;3(2):143-53.

46. Bigos SJ, Spengler DM, Martin NA, Zen J, Fisher L, Nachemson A, et al. Back injuries in industry: a retrospective study: III. employee-related factors. Spine $1986 ; 11(3): 252-6$.

47. Gilchrist I. Psychiatric and social factors related to low-back pain in general practice. Rheumatol Rehabil 1976;15:101-7.

48. Gilchrist I. Psychological aspects of acute low back pain in general practice. JR Coll Gen Pract 1983;33: 417-9.

49. Hägg GM, Suurküla J, Kilbom Å. Predictors for work related shoulder/neck disorders: a longitudinal study of female assembly workers. Stockholm: Arbetarskyddsverket, 1990. (Arbete och Hälsa; no 1990:10.)

50. Flodmark B, Aase G. Musculoskeletal symptoms and type $\mathrm{A}$ behavior in blue collar workers. $\mathrm{Br} \mathrm{J}$ Ind Med 1992:49:683-7.

51. Deyo RA, Bass E. Lifestyle and low-back pain; the influence of smoking and obesity. Spine 1989;14: $501-7$.

52. Troup JDG, Foreman TK, Baxter CE. The perception of back pain and the role of psychophysical tests of lifting capacity. Spine 1987:645-57.

53. Westerling D, Jonsson BG. Pain from the neck-shoulder region and sick leave. Scand J Soc Med 1980;8: $131-6$.

54. Tola S, Riihimäki H, Videman T, Viikari-Juntura E, Hanninen K. Neck and shoulder symptoms among men in machine operating, dynamic physical work and sedentary work. Scand J Work Environ Health 1988;14: $299-305$.

55. Bergenudd H, Lindgärde F, Nilsson B, Petersson CJ. Shoulder pain in middle age: a study of prevalence and relation to occupational work load and psychosocial factors. Clin Orthop Relat Res 1988;231:234-8.

56. Takala E-P, Viikari-Juntura E, Moneta G, Saarenmaa $\mathrm{K}$, Kaivanto K. Predictors for the natural course of neck-shoulder symptoms and headache in light sedentary work. In: Quéinnec Y, Daniellou F, ed. Designing for everyone: proceedings of the $1 \mathrm{l}$ th congress of the International Ergonomics Association, Paris, 1520 July 1991. London (etc.): Taylor \& Francis, 1991: $129-31$.

57. Ohara H, Nakagiri S, Itani T, Wake K, Aoyama $H$. Occupational health hazards resulting from elevated work rate situations. J Human Ergol 1976;5:173-82.

58. Kvarnström S, Halden M. Occupational cervicobrachial disorders in an engineering company. Scand $\mathbf{J}$ Rehabil Med 1983;suppl 8:1-114.

59. Ryan GA, Bampton M. Comparison of data process operators with and without upper limb symptoms. Community Health Stud 1988;12(1):63-8.

60. Kamwendo K, Linton SJ, Moritz U. Neck and shoulder disorders in medical secretaries: part I. pain prevalence and risk factors. Scand J Rehabil Med 1991; 23(3): $135-42$.

61. Ryan GA, Hage B, Bampton M. Postural factors, work organisation and musculoskeletal disorders. In: Buckle $\mathrm{P}$, ed. Musculoskeletal disorders at work: proceedings conference at the University of Surrey, Guildford,
April 1987. London (etc.): Taylor \& Francis, 1987: $251-3$.

62. Mäkelä $\mathbf{M}$, Heliövaara $M$, Sievers $K$, Impivaara $O$, Knekt P, Aromaa, A. Prevalence, determinants, and consequences of chronic neck pain in Finland. Am J Epidemiol 1991;134(1):1356-67.

63. Toomingas A, Theorell T, Michélsen H, Nordemar R. Associations between perceived psychosocial job factors and prevalence of musculoskeletal disorders in the neck and shoulder regions. In: Hagberg M, Kilbom A,, ed. Book of abstracts of the international scientific conference on prevention of work-related musculoskeletal disorders PREMUS, Sweden, May 12-14, 1992. Stockholm: Arbetarskyddsverket, 1992:307-9. (Arbete och hälsa; no 17.)

64. Veiersted KB, Westgaard RH. Work related risk factors for trapezius myalgia. In: Hagberg M, Kilbom A, ed. Book of abstracts of the international scientific conference on prevention of work-related musculoskeletal disorders PREMUS, Sweden, May 12-14, 1992. Stockholm: Arbetarskyddsverket, 1992:307-9. (Arbete och hälsa; no 17.)

65. Sauter SL, Gottlieb MS, Jones KC, Dodson VN, Rohrer KM. Job and health implications of VDT use: initial result of the Wisconsin - NIOSH study. Commun Assoc Comput Mach 1983;26(4):284-94.

66. Theorell T, Harms-Ringdahl K, Ahlberg-Hultén G, Westin B.Psychological job factors and symptoms from the locomotor system - a multicausal analysis. Scand J Rehabil Med 1991;23:165-73.

67. Kompier MAJ. Arbeid en gezondheid van stadsbuschauffeurs [Work and health of city bus drivers] [dissertation]. Delft: Eburon, 1988. (English summary.)

68. Leino P, Lyyra A. The effect of mental stress and social support on the development of musculoskeletal morbidity in the engineering industry. In: Sakurai H, Okazaki L, Omae I, ed. Occupational epidemiology. Amsterdam: Elseviers, 1990:267-72.

69. Pot F, Padmos P, Brouwers A. Determinants of the VDU operator's well-being. . In: Knave B, Widebäck PG, ed. Work with display units 86. Amsterdam: Elseviers, 1986.

70. Ursin H, Endresen IM, Ursin G. Psychological factors and self-reports of muscle pain. Eur J Appl Physiol 1988;57:282-90.

71. Hopkins A. Stress, the quality of work, and repetition strain injury in Australia. Work Stress 1990;4(2):12938.

72. Magni G, Caldieron C, Rigatti-Luchini S, Merskey $\mathrm{H}$. Chronic musculoskeletal pain and depressive symptoms in the general population: an analysis of the 1st national health and nutrition examination survey data. Pain 1990;43:299-307.

73. Smulders PGW. De arbeidssituatie van twaalf beroepsgroepen in de intramurale gezondheidszorg [Work and health in 12 professional groups in health care institutions]. Tijdschr Soc Gezondheid 1990;68:247-55.

74. Leino P. Symptoms of stress predict musculoskeletal disorders. J Epidemiol Community Health 1989;43(1) :293-300.

75. Burdorf A, Laan J. Comparison of methods for the assessment of postural load on the back. Scand J Work Environ Health 1991;17:425-9.

76. Wiktorin C, Karlqvist L, Nygård CH, Winkel J. Design and reliability of a questionnaire for estimation of physical load in epidemiologic studies. In: Quéinnic $Y$, Daniellou F, ed. Designing for everyone: proceedings of the 11 th congress of the Ergonomics Association, Paris 15-20 July 1991. London (etc): Taylor \& Francis, 1991:230-32.

Received for publication: 18 January 1993 